\title{
The misuse of antiretrovirals to boost pig and poultry productivity in Uganda and potential implications for public health
}

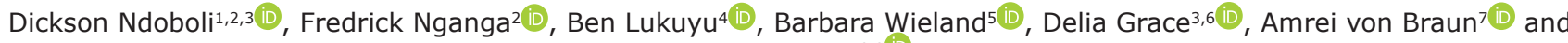 \\ Kristina Roese ${ }^{3,8}$ (iD
}

1. Central Diagnostic Laboratory, College of Veterinary Medicine, Animal Resources and Biosecurity, Makerere University, P.O. Box 7062, Kampala, Uganda; 2. Biosciences Eastern and Central Africa Hub, International Livestock Research Institute, P.O. Box 30709, Nairobi, Kenya; 3. Animal and Human Health Program, International Livestock Research Institute, P.O. Box 30709, Nairobi, Kenya; 4. Feed and Forage Development Program, International Livestock Research Institute, P.O. Box 24384, Kampala, Uganda; 5. Animal and Human Health Program, International Livestock Research Institute, P.O. Box 5689, Addis Ababa, Ethiopia; 6. Natural Resources Institute, University of Greenwich, Central Avenue, Chatham Maritime, Kent ME4 4TB, UK; 7. Division of Infectious Diseases and Tropical Medicine, University Hospital of Leipzig, Liebigstrasse 20, 04103 Leipzig, Germany; 8. Institute for Tropical Veterinary Medicine and Parasitology, Freie Universität Berlin, Robert-von-Ostertag-Strasse 7-13, 14163 Berlin, Germany.

Corresponding author: Dickson Ndoboli, e-mail: D.Ndoboli@cgiar.org

Co-authors: FN: f.nganga@cgiar.org, BL: b.lukuyu@cgiar.org, BW: b.wieland@cgiar.org, DG: d.randolph@cgiar.org, $A B:$ amrei.braun@medizin.uni-leipzig.de, KR: k.roesel@cgiar.org

Received: 26-08-2020, Accepted: 13-10-2020, Published online: 07-04-2021

doi: www.doi.org/10.14202/IJOH.2021.88-95 How to cite this article: Ndoboli D, Nganga F, Lukuyu B, Wieland B, Grace $D$, von Braun A, Roesel K (2021) The misuse of antiretrovirals to boost pig and poultry productivity in Uganda and potential implications for public health, Int. J. One Health, 7(1): 88-95.

\begin{abstract}
Background and Aim: Since 2015, local newspapers reported that pig and poultry farmers in Uganda use antiretroviral drugs (ARVs) to promote growth in animals and control diseases. This study was conducted to assess farmers' knowledge, attitude and perceptions about the use of antiretroviral drugs as boosters in pigs and poultry and the possibility of detecting the antiretroviral drugs in meat using available laboratory methods.

Materials and Methods: In 2019, a cross-sectional study was conducted in ten districts in Uganda. In 20 focus group discussions with 100 pig and poultry farmers and 70 animal health service providers, we assessed the use of ARV in livestock enterprises. Subsequently, samples of chicken, pigs, and animal feeds were collected from volunteer participants, and screened for residues of saquinavir, lopinavir, nevirapine, and efavirenz using liquid chromatography-tandem mass spectrophotometer.

Results: Participants in all ten districts were predominantly smallholder farmers supplying the local markets. All groups reported the use of ARVs in pigs and broiler birds but not in layer hens. In the absence of good quality feeds, the motivation for feeding ARVs was rapid animal weight gain, as well as the control of animal diseases, for which farmers have no alternative solutions. ARVs were obtained within the community for free, against cash, or in-kind payment. Residues of lopinavir were detected in four, and saquinavir in seven districts, and all three sample matrices.
\end{abstract}

Conclusion: Our study findings confirm anecdotal news reports on ARV use in livestock. While our findings are not generalizable to the whole country, they call for a representative follow-up. As the drugs were detected in tissues destined for human consumption, the potential risk to human health warrants further investigation.

Keywords: antimicrobial use, antiretroviral, growth promoters, pigs, poultry, residues.

\section{Introduction}

The majority of Ugandans depend on agriculture for food and income; the sector accounts for about $73 \%$ of the total employment, and transforming subsistence farming into commercial agriculture is one of the priorities of the Uganda National Poverty Eradication Plan [1]. The increase in livestock production is driven by increased demand for milk, meat, and eggs both locally and regionally in East Africa. The last national livestock

Copyright: Ndoboli, et al. This article is an open access article distributed under the terms of the Creative Commons Attribution 4.0 International License (http://creativecommons.org/licenses/ by/4.0/), which permits unrestricted use, distribution, and reproduction in any medium, provided you give appropriate credit to the original author(s) and the source, provide a link to the Creative Commons license, and indicate if changes were made. The Creative Commons Public Domain Dedication waiver (http:// creativecommons.org/ publicdomain/zero/1.0/) applies to the data made available in this article, unless otherwise stated. census conducted in 2008 showed an increase for both pig and poultry numbers of $28 \%$ each since 1999 .

Pig and poultry farming are particularly popular because they require little land and comparatively small start-up capital with cash returns after a relatively short time compared to ruminants. Moreover, the demand for pork and chicken is increasing, especially in urban centers. Because of this ready market for meat and eggs, farmers have replaced traditional but slowly maturing breeds with faster growing broiler breeds from high-income countries; for instance, farmers have turned to hybrid broilers that mature in 4 months compared to local birds that need 12 months until they reach market weight. Other practices to improve farm productivity include changed husbandry practices, such as animal confinement, vaccination, and/or adaptation of feed rations. 
Antimicrobial drugs include antibacterial (antibiotic), antifungal, and antiviral agents. In the livestock industry, antimicrobials are generally used for the treatment of animals with diagnosed illnesses; control of the spread of an illness on the farm in the event of an outbreak; prevention of the spread of an illness as livestock share water, shelter, feeds (metaphylaxis); prevention at times when livestock are at particular risk for infection such as during weaning; and growth promotion as some drugs help convert feed into muscle more quickly [2]. Globally, the use of antibiotics for growth promotion has been discussed controversially. In the European Union and many other countries, this led to a change in legislation and consequently, the complete ban on antibiotics as growth promoters in animal feeds; antivirals have not been part of this discussion $[3,4]$.

In Uganda, antimicrobial use is still poorly regulated and documented. Uncontrolled over-thecounter access to antimicrobials is common. As antimicrobial resistance is on the rise in the country, a National Action Plan on Antimicrobial Resistance was recently developed for implementation until 2023 [5]. However, baseline data on antimicrobial use in humans and animals are still limited, and resistance to antimicrobials is increasingly observed also in zoonotic pathogens isolated from animals and humans [6-8].

There have been anecdotal reports of East African farmers using antiretroviral drugs (ARVs) to promote growth in pigs and poultry; in the Ugandan news, this practice has been reported especially from the northern and central regions [9-15]. Farmers are cited that they use ARVs to control diseases such as African swine fever (caused by a double-stranded DNA virus called Asfivirus), and that they source the drugs from HIV-infected patients [13]. Recently, ARV residues have been detected in pork in Kampala and Lira districts in Uganda [16].

According to the Joint United Nations Program on HIV/AIDS, 1.4 Million people in Uganda were living with HIV in 2018 (prevalence 5.7\% among adults), and antiretroviral treatment (ART) coverage was $72 \%$ [17]. ART in Uganda is available to HIVinfected patient's free-of-charge and is largely funded by the U.S. President's Emergency Plan for AIDS Relief (PEPFAR). In-line with current guidelines by the World Health Organization, first-line treatment regimens for adults in Uganda consist of two nucleoside-reverse-transcriptase-inhibitors, either AZT/3TC or $\mathrm{TDF} / 3 \mathrm{TC}$, with either the integrase-inhibitor dolutegravir or alternatively the non-nucleoside-reverse-transcriptase-inhibitor (NNRTI) efavirenz [18]. Patients failing first-line treatment qualify for a switch to second-line treatment regimens which include protease inhibitors such as boosted lopinavir and darunavir. In general, acquired resistance to ARVs is mainly fostered by poor adherence, drug-drug interactions, and impaired absorption [19]. So far, most studies conducted in Uganda report high virological suppression rates among HIV-infected patients on treatment; however, the high prevalence of acquired drug resistance among patients with virological failure is of concern $[20,21]$.

The objectives of the study were to investigate whether ARVs are actually used by pig and poultry farmers in Uganda; and if so, why ARVs are used, how they are used, and from where they are sourced. In addition, the study investigated whether residues of ARVs can be detected in animal tissue destined for human consumption.

\section{Materials and Methods}

\section{Ethical approval and informed consent}

Ethical approval to conduct this study was obtained from the College of Veterinary Medicine, Animal Resources and Biosecurity at Makerere University, Kampala, Uganda (Ref.: SBLS/ REC/19/003), the Institutional Research Ethics Committee at the International Livestock Research Institute, Nairobi, Kenya (Ref.: ILRI-IREC2019-14), and the Institutional Animal Care and Use Committee at the International Livestock Research Institute in Nairobi, Kenya (Ref.: IACUC2019-11). In addition, we obtained permission from the Uganda National Council of Science and Technology to conduct research in the selected sites in Uganda (Ref.: A599). To transport samples from Uganda for analysis in Nairobi, Kenya, and in accordance with access and benefits sharing as detailed in the Nagoya Protocol, we received an export permit from the Commissioner at the Ministry of Agriculture, Animal Industry and Fisheries (Ref.: 00044609). To take samples into Kenya, we received an import permit from the Kenya Pharmacy and Poisons Board (CD2019000DVSVS070001585928). Aliquots of the samples have been retained in Uganda at the Central Diagnostic Laboratory, College of Veterinary Medicine, Animal Resources and Biosecurity at Makerere University. Informed consent was obtained from each participant.

\section{Study period, design and area}

From January to August 2019, a cross-sectional study using qualitative and quantitative methods was conducted in ten districts in Uganda (Figure-1). The districts were selected based on anecdotal reports in the local news about ARV use in pig and poultry farms. Two other districts were invited to participate, but the district government was not available to collaborate.

\section{Qualitative data collection}

Participatory methods adapted from social science have been successfully used in Uganda in characterizing animal health problems, identifying diseases that have never been reported from the country before, or characterizing drivers of human 


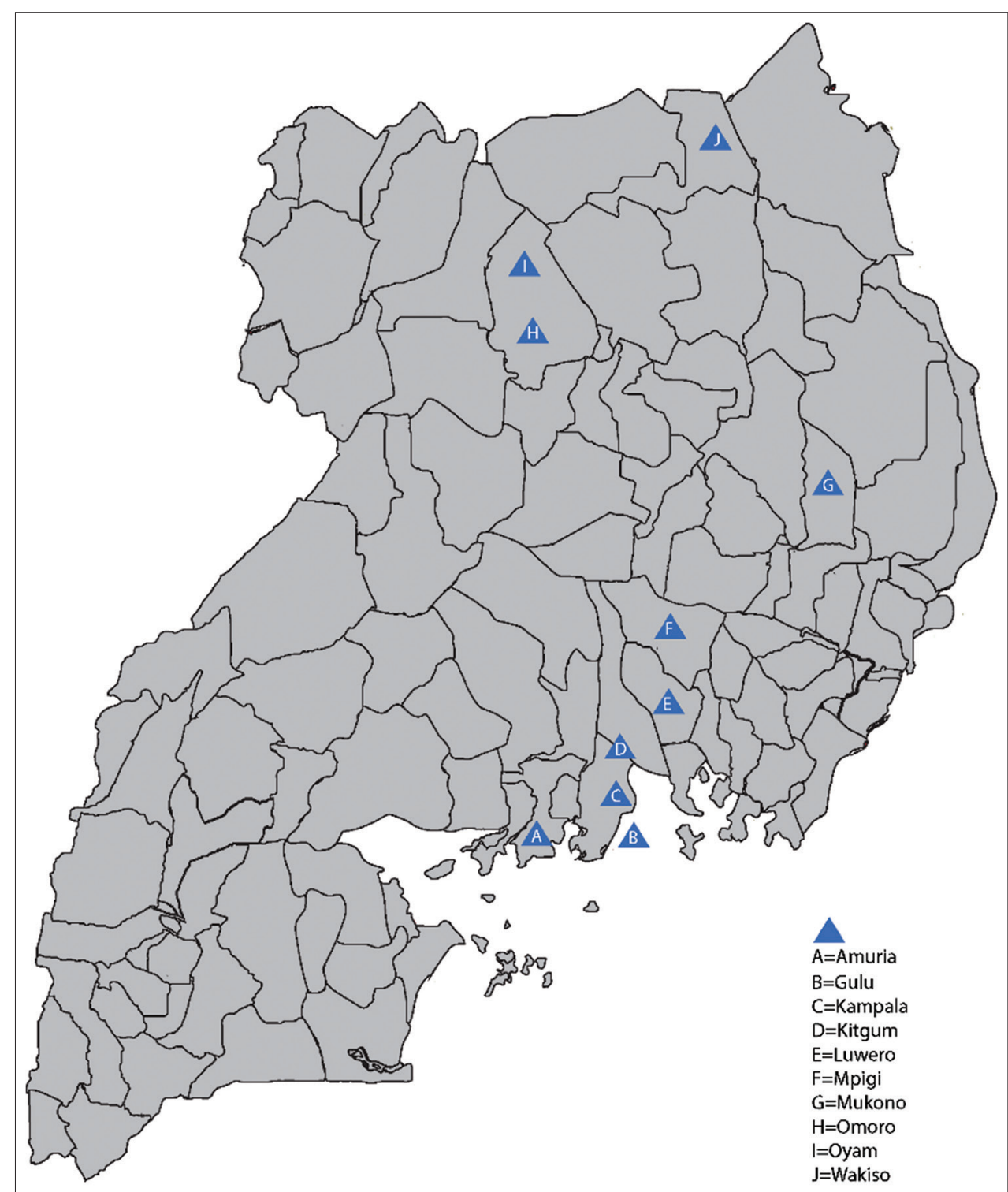

Figure-1 : Districts in Uganda where the study was conducted between January and August 2019 [Source: ILRI/Bethlehem Alemu].

consumption behavior [22-24]. Discussions with small groups of similar socio-cultural and socio-economic backgrounds help in better understanding specific problems, their context and approaches to solving them within a community. A generic tool to assess knowledge, attitudes, and practices on antimicrobial use guided the development of a focus group discussion (FGD) guide for this study [25]. A chart showing pictures of locally sold antimicrobials, including ARVs, assisted the identification of drugs used by the farmers.

In each district, one FGD was organized with ten pig and poultry farmers. They had been identified by the local veterinary officers because they were suspected or known to use antimicrobials in their animals. In these discussions, farmers debated feed management, disease management, extension services, challenges in improving farm productivity, and how to cope with them. When discussing the use of antimicrobials as growth promoters, they were probed on different uses of different drugs, availability, accessibility, as well as knowledge on the application, and practices post-application such as withdrawal periods.

For reasons of triangulation, in each district a second FGD was organized with four to ten animal health service providers (AHSPs) whose catchment area includes the farmers in the first group. These AHSP are usually registered with the district government and are usually private veterinarians (Bachelor of Veterinary Medicine), diploma holders in animal health or livestock science and artificial insemination, or certificate holders in animal husbandry. The discussion points were similar to those in the farmer FGDs and covered the different types of farm input used by farmers, major challenges to improve farm productivity, how farmers cope with these challenges, farmers' knowledge on antimicrobial drugs, commonly used antimicrobials, as well as their purpose, and sources of these drugs. Probing was done specifically on antimicrobials, including ARVs. 
Before the FGDs, the study was explained, and verbal or written consent given. A note taker documented highlights of the discussion and non-audible results such as hand counts, or nodding. All discussions were audio-recorded in local language and later transcribed and translated into English. The transcripts were manually analyzed by content analysis.

\section{Quantitative data collection}

Sample collection

Tissue samples were collected for testing from pigs and poultry at farms of volunteering farmers who had participated in the FGDs. If the volunteer farmers planned on slaughtering a chicken or pig, the researchers were called to collect the sample at the time of slaughter. In that case, $25 \mathrm{~g}$ of chicken liver was collected from freshly slaughtered chicken, and $25 \mathrm{~g}$ of pig muscle tissue was collected from slaughtered pigs. If farmers did not plan on slaughtering, blood was collected from live animals, for example, $5-7 \mathrm{~mL}$ from the ear vein in pigs and $5 \mathrm{~mL}$ from the wing vein in chicken, into clotting tubes (BD vacutainer, Berkshire, UK) for serum harvesting. All vials were labeled and transported in an icebox (at $4^{\circ} \mathrm{C}$ ) to the Central Diagnostic Laboratory at the College of Veterinary Medicine, Animal Resources and Biosecurity in Kampala for further processing. Meat and liver juice was extracted by freeze-thawing each sample overnight at $-30^{\circ} \mathrm{C}$; then $2 \mathrm{~mL}$ of each sample was stored in cryotubes (Nalgene cryogenic vials, Thermo Fisher Scientific, Waltham, Massachusetts, USA) and shipped to Nairobi, where analysis was performed at the Biosciences eastern and central Africa (BecA-) Hub hosted by the International Livestock Research Institute, Nairobi-Kenya.

\section{Residue quantification using liquid chromatogra- phy-tandem mass spectrometry (LC-MS/MS)}

\section{Reagents and chemicals}

All ARV standards used were of the highest purity available. Lopinavir, saquinavir mesylate, nevirapine, and efavirenz were purchased from SigmaAldrich UK through a third-party agent. This panel of ARVs was selected due to availability. Agilent Quick Easy Cheap Effective Rugged Safe (QuEChERS) dSPE EMR-Lipid kits (5982-1010) were purchased through Chemetrix Pty Ltd. (Johannesburg, South Africa). Individual salts (sodium chloride and anhydrous magnesium sulfate) that constitute Agilent Bond Elute Final Polish for Enhanced Matrix RemovalLipid (p/n 5982-0101) were separately procured from Sigma-Aldrich UK and mixed in their corresponding ratios ( $2 \mathrm{~g}$ of salt mix, i.e., $4: 1 \mathrm{MgSO}_{4}: \mathrm{NaCl}$ ) in $15 \mathrm{~mL}$ round-bottomed tubes.

High-performance LC (HPLC)-grade water was obtained from water passed through a MilliQ water purification system (Millipore Ltd., Bedford, MA, USA). Chromasolv grade acetonitrile and formic acid (>98\%) were also obtained from Sigma-Aldrich.
For details on instrumentation, multiple reaction monitoring optimization and chromatographic conditions are shown in Supplementary material.

\section{Sample preparation}

Sample preparation was done according to the QuEChERS extraction protocol as adapted by Zhao and Lucas 2015 [26] with minor modifications (Supplementary materials). The application of QuEChERS kits, particularly the enhanced matrix removal dispersive solid phase kit with the extraction for sample extraction and cleanup before LC-MS/MS analysis, has proved to be an efficient method to detect certain ARV residues in serum and juice from edible tissues as well as animal feed extracts. In the past, several studies have shown efficiency of the method in detecting residues of anti-parasitic drugs in meat with very high sensitivity, specificity, and selectivity [27].

\section{Validation study}

A validation study was carried out for the four analytes before analysis of samples on chicken liver serum. Parameters investigated were linearity, matrix effect, and extraction recovery (Supplementary material).

In clinical practice, the measurement of plasma concentrations of ARVs in the context of therapeutic drug monitoring (TDM) can help to identify patients with sub-therapeutic, toxic, or appropriate drug concentrations. The drug classes protease inhibitors and NNRTI generally qualify for TDM as there is a dose-response relationship, a defined therapeutic range, and low intra-patient variability in plasma concentrations [28]. For the study sample analysis, we chose a panel of four drugs from the drug classes protease inhibitors and NNRTI as they qualify for TDM in human medicine and are available for testing in our setting. Ahead of the sample analysis, we did not know which drugs were used by the farmers. The protease inhibitors saquinavir and lopinavir, and the NNRTI efavirenz and nevirapine were chosen. While saquinavir is not part of international treatment guidelines due to more efficient and tolerable alternatives, lopinavir continues to be an important treatment component in adults (second-line) and children (alternative first-line). The NNRTI efavirenz is used in the first-line treatment of adults and second-line treatment of children, while nevirapine is used less often in adults these days, it is still recommended in first-line treatment of neonates and certain prevention of mother-to-child programs [18].

\section{Results}

\section{ARV residues in edible tissues}

Using LC-MS/MS 11/200 pork and chicken samples $(5.5 \%)$ tested positive for residues of saquinavir, and $5 / 200$ pork and chicken samples $(2.5 \%)$ tested positive for lopinavir. None of the samples tested positive for nevirapine and efavirenz. In three out of the 
ten districts, no ARV residues were detected. Table-1 shows the details by sample matrix.

\section{The use of ARVs by poultry and pig farmers}

From the 12 districts, where the practice of ARV use in livestock had been reported informally, ten district veterinarians agreed to participate in the study and identified farmers known to use antimicrobials to boost their farm's productivity. From each of the ten FGDs, farmers volunteered to have their animals and/or feeds sampled. Details are given in Table-2. In the following section, we abstain from indicating proportions to avoid misperceptions about the generalizability of the results.

Both farmers and AHSPs confirmed that ARVs are used in all the study districts; but the practice was particularly rampant in Mukono, Mpigi, and Wakiso districts in the central region.

Most of the poultry farmers in the discussions were small-scale farmers who kept below 500 birds for sale of meat or eggs to the local and regional markets. All farmers kept local chicken for home consumption and "kroilers," a hybrid breed, for sale. Day-old-chicks are supplied countrywide by four companies, and usually vaccinated against infectious diseases such as Haemophilus paragallinarum (infectious coryza), Salmonella Gallinarum (fowl typhoid), and Salmonella Pullorum (white diarrhea). While large farms hire workers, small-scale farmers usually manage their flocks with assistance from family members. Most of the poultry farmers did not know what antimicrobials do but used them continuously, especially antibiotics (results not published). ARVs are used in broiler birds but not in layers, by mixing them in water. They are perceived to promote growth and to prevent or treat Newcastle disease virus and Mycoplasma spp. infections in poultry. Reported side effects in chickens are loss of taste, increased fat content, and sudden death; AHSPs reported that during postmortem, birds were found with ruptured heart muscles.

Most pig farmers in the FGDs were small-scale farmers who keep 1-20 pigs; a few farmers in the central region kept between 100 and 400 pigs. Pig farmers usually buy piglets to grow them for the meat market (growers-fatteners), only a few strictly produce piglets for sale (breeders). Pig farms are also managed mainly by the farmers with help from family members, while large-scale farmers have hired help. ARVs are used as additives to feeds and water; in some instances, a whole pack of 30 tablets would be grinded and mixed into $100 \mathrm{~kg}$ of maize bran and given to the pigs continuously. In some districts, it is administered as a vaccine against African swine fever by the AHSPs. Some farmers in Mukono district reported that "some of their friends who use ARVs, often give two tablets to piglets to accelerate growth and weight gain while the sow is given tablets orally to increase milk production for the piglets." Side effects reported in pigs are abortions, increased fat contents and tasteless meat. AHSPs report that before slaughter, pigs look heavy but after slaughter, the carcass shows a high fat-tomuscle ratio.

In Kampala, AHSPs reported that the use of ARVs is a rapidly growing practice including on their own farms as they are convinced of their effectiveness in boosting weight gain. The highest levels of

Table-1: Different matrices tested for a panel of antiretroviral residues using liquid chromatography mass spectrophotometer tandem.

\begin{tabular}{|c|c|c|c|c|c|}
\hline Sample matrix & $\begin{array}{c}\text { Number of } \\
\text { samples tested }\end{array}$ & $\begin{array}{c}\text { Saquinavir } \\
\text { positive (\%) }\end{array}$ & $\begin{array}{c}\text { Lopinavir } \\
\text { positive (\%) }\end{array}$ & $\begin{array}{c}\text { Nevirapine } \\
(\%)\end{array}$ & $\begin{array}{c}\text { Efavirenz } \\
(\%) \\
\end{array}$ \\
\hline Chicken liver & 63 & $4(6.35)$ & $1(1.59)$ & .. &.$\cdot$ \\
\hline Chicken serum & 13 &.. & $1(7.69)$ & .. &.. \\
\hline Pig meat & 27 & $5(17.24)$ & .. & .. &.$\cdot$ \\
\hline Pig serum & 39 & $1(2.56)$ & $2(5.13)$ & .. &.. \\
\hline Feed samples & 34 & $1(2.94)$ & $1(2.94)$ & .. & .. \\
\hline
\end{tabular}

Table-2: Composition of the focus group discussions and samples obtained.

\begin{tabular}{|c|c|c|c|c|c|c|c|c|c|}
\hline \multirow[t]{2}{*}{ Region } & \multirow[t]{2}{*}{ District } & \multirow{2}{*}{$\begin{array}{l}\text { Total number of } \\
\text { Animal Health Service } \\
\text { Providers ( } \% \text { women) }\end{array}$} & \multirow{2}{*}{$\begin{array}{c}\text { Total number } \\
\text { of farmers } \\
\text { (\% women) }\end{array}$} & \multirow{2}{*}{$\begin{array}{c}\text { Number of } \\
\text { volunteer } \\
\text { farms sampled }\end{array}$} & \multicolumn{5}{|c|}{ Number of samples obtained } \\
\hline & & & & & $\begin{array}{c}\text { Chicken } \\
\text { liver }\end{array}$ & $\begin{array}{c}\text { Chicken } \\
\text { serum }\end{array}$ & $\begin{array}{c}\text { Pig } \\
\text { meat }\end{array}$ & $\begin{array}{c}\text { Pig } \\
\text { serum }\end{array}$ & Feeds \\
\hline \multirow[t]{5}{*}{ Central } & Kampala & $10(\cdot \cdot)$ & $10(70.0)$ & 3 & 10 & 5 & 3 & 7 & 2 \\
\hline & Luweero & $5(\cdot \cdot)$ & $10(10.0)$ & 4 & 11 & 0 & 1 & 9 & 5 \\
\hline & Mpigi & $9(\cdot)$ & $10(60.0)$ & 7 & 7 & 7 & 3 & 4 & 4 \\
\hline & Mukono & $10(10.0)$ & $10(\cdot \cdot)$ & 5 & 2 & 6 & 2 & 9 & 5 \\
\hline & Wakiso & $7(0)$ & $10(60.0)$ & 6 & 5 & 5 & 5 & 6 & 5 \\
\hline Eastern & Amuria & $5(\cdot \cdot)$ & $10(80.0)$ & 3 & 4 & 0 & 4 & 2 & 3 \\
\hline \multirow{4}{*}{ Northern } & Gulu & $7(28.6)$ & $10(50.0)$ & 4 & 10 & 9 & 5 & 4 & 1 \\
\hline & Kitgum & $8(12.5)$ & $10(40.0)$ & 2 & 8 & 0 & 4 & 0 & 4 \\
\hline & Omoro & $5(\cdot \cdot)$ & $10(70.0)$ & 5 & 4 & 0 & 2 & 4 & 2 \\
\hline & Oyam & $4(\cdot \cdot)$ & $10(100.0)$ & 4 & 5 & 0 & 0 & 5 & 2 \\
\hline Total & 10 & $70(5.7)$ & $100(54.0)$ & 43 & 66 & 23 & 29 & 50 & 33 \\
\hline
\end{tabular}


ARV use were reported among broiler farmers around Kampala, and in pig and broiler farms in Wakiso district. The main drivers were lack of good quality feeds as well as efficient vaccines against Newcastle disease virus in chicken and African swine fever in pigs. It is believed that a drug that is able "to minimize the notorious HIV in humans would easily keep off the minor poultry and pig viruses." AHSPs in Gulu reported that in one village ARVs are used so often that "farmers in the area have long forgotten about the problems of African swine fever and Newcastle disease."

Both pig and poultry farmers have not obtained any formal training in pig or poultry keeping, and usually learn about husbandry, especially feeding and disease management, on the job and by trial and error. Both poultry and pig farmers report that consulting professional veterinarians are expensive and hard to access while paraveterinarians are usually more available and affordable.

As the main source of ARVs, farmers indicated they obtain the drugs from patients on ART. These patients share their drugs with their own animals or with other farmers, either free of charge or against cash or in-kind payment. Other sources are medical centers, or dispensaries, where the drugs are stored, and especially expired ARVs are sold to interested clients without prescriptions. ARVs were reported to be sold to the farmers at varying prices ranging from 0.20 to 2.00 USD per tablet in the different districts. The AHSPs confirmed that the main sources of ARV tablets are HIV-infected patients on treatment, health centers, other AHSPs, and stocks of expired medicines. One AHSP in Wakiso blamed the circulation of drugs on "corrupt staff at medical centers who sell drugs to people who are not on therapy."

Farmers have mixed perceptions about using ARVs in pigs and chicken. Some think it is a bad practice as ARVs are drugs for use in humans and should not be used in animals. Others think that because the drugs are for use in humans, giving them to animals cannot have negative consequences for humans. While the first group of farmers would not wish to eat meat of animals fed on ARVs, the second group would not mind eating such meat. These perceptions existed in all communities, regardless of the educational standard, although in the rural communities the safety and quality of meat is not a primary determinant of consumption.

\section{Discussion}

Our study findings confirm that farmers in Uganda are indeed using ARVs to increase pig and poultry farm productivity. Farmers have used, seen and heard their friends use ARVs in this context; AHSPs are aware of farmers giving ARVs to their animals and partly support the practice.

Participatory methods proved feasible to discuss topics as sensitive as drug misuse on livestock farms. While at first, FGD participants were reserved in sharing their experience, the group setting and the experience that drug misuse is not uncommon made them feel less exposed and discuss openly.

This is the second study reporting the use of ARVs in livestock in Uganda. Nakato et al. [16] examined 361 porcine pig plasma samples from two regional pig abattoirs for residues of efavirenz, nevirapine, and tenofovir using HPLC: About 13.6\% of the samples tested positive for efavirenz, and $13.9 \%$ tested positive for nevirapine.

While HPLC has been the primary detection method for studying ARV metabolites in human body fluids; LC-MS/MS has been adopted in recent years as a method capable of detecting low concentrations of analytes and broadening the spectrum of detectable drugs. With our established protocol, it is possible to conduct large surveys to understand the magnitude of the malpractice and assess the level of public health implications. The government of Uganda has LC-MS/MS in place and once the protocol is set up, analysis of one sample would cost ca. 14 US\$.

In Uganda prices for chicken and pork are now slightly higher than beef and goat meat. In East Africa generally, pork and chicken costs nearly 25\% more than fish, $45 \%$ more than beef, and 300\% more than beans. A kilogram of beef is about 9000 Ugandan Shillings (ca. 2.50 US\$) and yet pork goes for 12,000 Ugandan Shillings (ca. 3.20 US\$). To maximize profits farmers are faced with the challenge of attaining the maximum desired market with minimal input of feeds and in the shortest time possible. The qualitative study shows that farmers adopt practices like this out of lack of knowledge. They have never been taught good agricultural practices, and in the absence of quality feeds and vaccines make use of means available to them.

Thus, their main motivations to give ARVs to their animals were weight gain and disease prevention. Farmers claim that ARVs are very effective in increasing the bodyweight of broilers and pigs. This perception most likely arises from the fact that HIVinfected patients typically gain weight under ART either due to health recovery or as a drug side effect. As confirmed by the AHSPs in this study, post slaughter, it becomes visible that the heavier weight of an animal may be caused by a shifted fat-muscle ratio. The negative consequences on the health of the animals can only be assumed from our findings and call for a thorough investigation of these practices.

According to the farmers, giving ARVs to the animals was effective in treating African swine fever virus, a double-stranded DNA virus, in pigs, and Newcastle disease virus, a single-stranded RNA virus, in poultry. However, the efficacy of ARVs in treating infection with African swine fever virus or Newcastle disease virus has so far not been experimentally validated.

The fact that some farmers report sharing their own ART with other farmers and/or their own animals 
is worrisome, as we must assume that the HIV-infected farmers are not taking every dose. Poor adherence fosters drug resistance, which, in turn, may result in complicated treatment regimens or even untreatable HIV infections [21]. HIV-infected farmers engaged in these practices need expert counseling, as well as viral load monitoring.

From a pharmacological standpoint, it can be assumed that the small drug concentrations detected in animal samples are destroyed by heat administered during cooking, frying, baking, etc. We, therefore, do not assume that consumers of the sufficiently heated products are subjected to relevant drug concentrations which could harm untreated HIV-infected persons through the development of HIV drug resistance. However, this aspect should be kept in mind and be investigated on a larger scale, as it may depend on factors such as the drug doses given to the animals, the individual meat preparation techniques, as well as the age and physical constitution of the consumer.

We were able to confirm the use of ARVs in pigs and chicken. While this practice is harmful to HIV-infected farmers who give part of their treatment away, it could also be harmful to the animals. Nevertheless, our study had limitations. As we did not know which ARVs to expect we chose four, of which two were detected. Whether other ARV is also used by the farmers is currently unknown, but can be assumed, as Nakato et al. [16], for instance, did detect efavirenz and nevirapine in their sample. Most likely the farmers use varying drug regimens depending on availability. Saquinavir, for instance, is not part of treatment guidelines, but seems to be given away by pharmacies for this purpose. To complete the picture, further research which includes the testing of the actual tablets given to the farmers, as well as a broader spectrum of drugs is warranted. While it is important to note that the results are not generalizable to the entire country of Uganda, they call for a rigorous baseline study to assess the full scope of the problem.

\section{Conclusion}

Since 2015, local newspapers reported that pig and poultry farmers in Uganda use ARVs to promote growth in animals and control diseases. Similar practices are also reported from other countries in East Africa. A mixed-methods approach aimed at confirming whether this reflects the reality and if so, what are the drivers for this behavior and which potential public health implications this could have. The study was only implemented in districts where the practice of feeding ARVs to livestock and poultry has been informally reported from. In collaboration with district officials, farmers were invited to participate and volunteer to provide samples of their animals. The study was able to confirm anecdotal reports and identified the chemical hazard in edible tissues. However, to quantify the risk to human health, for instance, the contribution to the emergence of resistance to ART in
HIV-infected patients requires further experimental and large-scale epidemiological studies.

\section{Authors' Contributions}

$\mathrm{DN}$ and KR contributed to idea formulation, data collection, data interpretation, and writing of the manuscript. FN and DN contributed to quantitative data analysis and interpretation. BL and BW contributed to data collection and writing of the manuscript. DG and $\mathrm{AB}$ contributed to data interpretation and manuscript writing. All authors read and approved the final manuscript.

\section{Acknowledgments}

The work was funded through the CGIAR Research Programs on Livestock and Agriculture for Nutrition and Health with support of the Africa Biosciences Challenge Fund fellowship program by the BecA-Hub hosted by the International Livestock Research Institute. We also acknowledge the CGIAR Fund Donors (https://www.cgiar.org/funders). The funding source was not involved in the planning or implementation of the study.

This study was also partly supported by the BecA-ILRI Hub through the Africa Biosciences Challenge Fund (ABCF) program. The ABCF Program was funded by the Australian Department for Foreign Affairs and Trade (DFAT) through the BecACSIRO partnership; the Syngenta Foundation for Sustainable Agriculture (SFSA); the Bill \& Melinda Gates Foundation (BMGF); the UK Department for International Development (DFID) and the Swedish International Development Cooperation Agency (Sida)."

\section{Competing Interests}

The authors declare that they have no competing interests.

\section{Publisher's Note}

Veterinary World (Publisher of International Journal of One Health) remains neutral with regard to jurisdictional claims in published map and institutional affiliation.

\section{References}

1. Ministry of Agriculture, Animal Industry and Fisheries (MAAIF), Uganda Bureau of Statistics (UBOS). (2009) The National Livestock Census Report 2008, Entebbe, Kampala, Uganda. Available from: https://www.ubos.org/wp-content/ uploads/publications/05_2019the_national_livestock_census_report_2008.pdf. Retrieved on 25-09-2020.

2. Castanon, J.I.R. (2007) History of the use of antibiotic as growth promoters in European poultry feeds. Poult. Sci., 86(11): 2466-2471.

3. European Commission. (2005) Ban on Antibiotics as Growth Promoters in Animal Feed Enters into Effect, Press Release Data Base. europa.eu/rapid/press-release_ip-051687 en.htm. Retrieved on 18-09-2019.

4. World Organization for Animal Health. (2018) OIE Annual Report on Antimicrobial Agents Intended for Use in animals, Paris, France. Available from: https://www.oie.int/ 
en/for-the-media/press-releases/detail/article/new-report-shows-global-shift-in-use-of-antibiotics-in-animals. Retrieved on 18-09-2019.

5. Government of Uganda. (2018) Antimicrobial Resistance National Action Plan 2018-2023. Available from: https:// www.cddep.org/wp-content/uploads/2018/12/GoU_AMRNAP.pdf. Retrieved on 08-03-2021.

6. Afema, J.A., Byarugaba, D.K., Shah, D.H., Atukwase, E., Nambi, M. and Sischo, W.M. (2016) Potential sources and transmission of salmonella and antimicrobial resistance in Kampala, Uganda. PLoS One, 11(3): e0152130.

7. Weiss, D., Wallace, R.M., Rwego, I.B., Gillespie, T.R., Chapman, C.A., Singer, R.S. and Goldberg, T.L. (2018) Antibiotic-resistant Escherichia coli and class 1 integrons in humans, domestic animals, and wild primates in Rural Uganda. Appl. Environ. Microbiol., 84(21): e01632.

8. Odoch, T., Sekse, C., L'Abee-Lund, T., Hansen, H.K., Kankya, C. and Wasteson, Y. (2018) Diversity and antimicrobial resistance genotypes in non-typhoidal salmonella isolates from poultry farms in Uganda. Int. J. Environ. Res. Public Health, 15(2): 324.

9. Obonyo, O. (2013) Shock of Farmers Using AntiRetroviral (ARV) drugs, to "fatten" Chicken, Stand. Digit. Available from: https://www.standardmedia.co.ke/article/2000096749/shock-of-farmers-using-arvs-to-fattenchicken. Retrieved on 18-09-2019.

10. Hatari! (2013) Wafugaji Kutumia ARV (Dawa ya Ukimwi) Kunenepesha Kuku, Phars Blogspot. Available from: https:// www.phars.blogspot.com/2013/11/hatari-wafugaji-kutumia-arv-dawa-ya 9230.html. Retrieved on 18-09-2019.

11. Opoka, D. (2018) Uganda: Kitgum Locals Use Arvs to Brew Alcohol, "Fatten" Pigs, Daily Monitor Newspaper. Available from: https://www.monitor.co.ug/news/national/ kitgum-locals-use-arvs-to-brew-alcohol-fatten-pigs-/688334-4889624-nht7m6/index.html. Retrieved on 18-09-2019.

12. Oketch, B. (2013) Residents Use ARVs to Fatten Pigs, Daily Monitor Newspaper. Available from: https://www. monitor.co.ug/uganda/news/national/kitgum-locals-usearvs-to-brew-alcohol-fatten-pigs--1794894. Retrieved on 08-03-2021.

13. Oketch, B. (2016) Lira Farmers Share ARVs with Their Pigs, Daily Monitor Newspaper. Available from: https:// www.monitor.co.ug/specialreports/lira-farmers-share-arvspigs/688342-3172864-u57a0pz/index.html. Retrieved on 18-09-2019.

14. URN. (2017) Farmers Feed Pigs on ARVs, The Observer. Available from: https://www.observer.ug/news/headlines/53961-farmers-feed-pigs-on-arvs. Retrieved on 18-09-2019.

15. Odongo, R. (2016) Lira Farmers Probed for Feeding Pigs on ARV Drugs, URN. Available from: https://www.ugandaradionetwork.com/story/lira-district-probing-use-of-arvdrugs-to-feed-pigs-by-farmers. Retrieved on 18-09-2019.

16. Nakato, R., Tumwine, J.K., Nanzigu, S., Naluyima, S., Buzibye, A., Alinayitwe, L., Makoha, C. and Mukonzo, J.K. (2020) Antiretroviral drugs found in pork on Ugandan market: Implications for HIV/AIDS treatment. One Health, 9(ePub): 100125.

17. UNAIDS. (2018) Country Profile Uganda. Available from: https://www.unaids.org/en/regionscountries/countries/ uganda. Retrieved on 18-09-2019.

18. World Health Organization. (2019) Update of Recommendations on First-and Second-Line Antiretroviral Regimens, Policy Brief, WHO/CDS/HIV/19.15. Available from: https://www.who.int/hiv/pub/arv/arv-update-2019policy/en/. Retrieved on 08-03-2021.

19. WHO/CDC/Global Fund. (2017) HIV Drug Resistance Report 2017.

20. Omooja, J., Nannyonjo, M., Sanyu, G., Nabirye, S.E., Nassolo, F., Lunkuse, S., Kapaata, A., Segujja, F., Kateete, D.P., Ssebaggala, E., Bbosa, N., Aling, E., Nsubuga, R.N., Kaleebu, P. and Ssemwanga, D. (2019) Rates of HIV-1 virological suppression and patterns of acquired drug resistance among fisherfolk on first-line antiretroviral therapy in Uganda. J. Antimicrob. Chemother., 74(10): 3021-3029.

21. von Braun, A., Sekaggya-Wiltshire, C., Bachmann, N., Ssemwanga, D., Scherrer, A.U., Nanyonjo, M., Kapaata, A., Kaleebu, P., Günthard, H.F., Castelnuovo, B., Fehr, J. and Kambugu, A. (2018) HIV-1 drug resistance among Ugandan adults attending an urban out-patient clinic. $J$. Acquir. Immune Defic. Syndr., 78(5): 566-573.

22. Dione, M.M., Ouma, E.A., Roesel, K., Kungu, J., Lule, P. and Pezo, D. (2014) Participatory assessment of animal health and husbandry practices in smallholder pig production systems in three high poverty districts in Uganda. Prev. Vet. Med., 117(3-4): 565-576.

23. Musewa, A., Roesel, K., Grace, D., Dione, M. and Erume, J. (2018) Detection of Erysipelothrix rhusiopathiae in naturally infected pigs in Kamuli District, Uganda. Rev. Elev. Med. Vet. Pays Trop., 71(1-2): 97.

24. Roesel, K., Ejobi, F., Dione, M., Pezo, D., Ouma, E., Kungu, J., Clausen, P.H. and Grace, D. (2019) Knowledge, attitudes and practices of pork consumers in Uganda. Glob. Food Secur., 20(ePub): 26-36.

25. Wieland, B., Dione, M., Gemeda, B.A., Fèvre, E., Grace, D., Omoya, L., Ström, G., Lindahl, E. and Magnusson, U. (2018) Harmonisation of data collection on knowledge, attitude and practices of antimicrobial use in livestock production. In: The $15^{\text {th }}$ International Symposium of Veterinary Epidemiology and Economics. p.424. Available from: http://www.isvee.net/wp-content/uploads/2018/10/ isvee15_abstract-book.pdf. Retrieved on 18-09-2019.

26. Zhao, L. and Lucas, D. (2015) Multiresidue Analysis of Veterinary Drugs in Bovine Liver by LC-MS/MS Agilent Bond Elute Enhanced Matrix Removal-Lipid, Application Note. Available from: https://www.agilent.com/cs/library/ applications/5991-6096en.pdf. Retrieved on 25-09-2020.

27. Wei, H., Tao, Y., Chen, D., Xie, S., Pan, Y., Liu, Z. Huang, L. and Yuan, Z. (2015) Development and validation of a multi-residue screening method for veterinary drugs, their metabolites and pesticides in meat using liquid chromatography-tandem mass spectrometry. Food Addit. Contam. Part A Chem. Anal. Control Expo. Risk Assess., 32(5): 686-701.

28. Kredo, T., van der Walt, J.S., Siegfried, N. and Cohen, K. (2009) Therapeutic drug monitoring of antiretrovirals for people with HIV. Cochrane Database Syst. Rev., 3: CD007268. 